\title{
Research Concerning the Predictive Evaluation of the Motor Moment at the Crankshaft of the Conventional Sucker Rod Pumping Units
}

\author{
DORIN BADOIU, GEORGETA TOMA* \\ Petroleum-Gas University of Ploiesti, 39 Bucuresti Blvd., 100680, Ploiesti, Romania
}

\begin{abstract}
It is well known that the variation on the cinematic cycle of the motor moment at the crankshaft of the conventional pumping units characterizes their proper functioning. In the paper it was developed a predictive calculation model of the motor moment at the crankshaft depending on the force at the polished rod. The estimation of the predictive model parameters has been done by minimizing a function that contains the calculus model errors. The experimental records have been processed with the program Total Well Management. The simulations have been performed with a computer program developed by the authors using Maple programming environment.
\end{abstract}

Keywords: sucker rod pumping unit, motor moment, predictive model

The variation on the cinematic cycle of the motor moment at the crankshaft of the conventional pumping units characterizes their proper functioning [1]. The calculation of the motor moment implies the knowledge of the dimensions of the cinematic elements of the pumping units mechanism, their masses and moments of inertia, the position of their mass centers and the variation on the cinematic cycle of the force at the polished rod. A series of interesting results regarding the determination of the variation on the cinematic cycle of the motor moment at the crankshaft are presented in [2-6].

Some of the parameters involved in calculating the motor moment are not known precisely, especially those relating to the inertia of the pumping units components (the moments of mass inertia and the position of the mass centers of some components such as the rocker head). On the other hand it is necessary to carry out beforehand the cinematic analysis of the pumping unit mechanism that is investigated for determining the angular speeds and accelerations of the component elements and the speeds and accelerations of the application points of the various loads (forces of inertia, weights and the force at the polished rod). Therefore, the calculation of the motor moment becomes extremely laborious and for satisfactory results it often requires prior identification of the less known values of some parameters that occur in the calculations [5].
In this paper it is developed a predictive calculation model of the motor moment at the crankshaft depending only on the force at the polished rod in the case of a C640D-305-120 pumping unit. The estimation of the model parameters is done with the least sum of squared errors method. For processing the experimental records itis used the program Total Well Management [7]. The simulations have been performed with a computer program developed by the authors using Maple programming environment [8] .

\section{Experimental part}

The experimental results have been recorded at a well serviced by a C-640D-305-120 pumping unit manufactured by Lufkin [9] (fig. 1). Processing experimental results was achieved with Total Well Management program [7].

In establishing the parameters of the predictive calculation model of the motor moment at the crankshaft were used the records concerning the variation of the force at the polished rod for four strokes: stroke 50 (fig. 2), stroke 51 (fig. 3), stroke 52 (fig. 4) and stroke 53 (fig. 5). The results obtained with the predictive calculation model were compared with the experimental records of the motor moment at the crankshaft for the four above mentioned strokes (fig. 2-5).

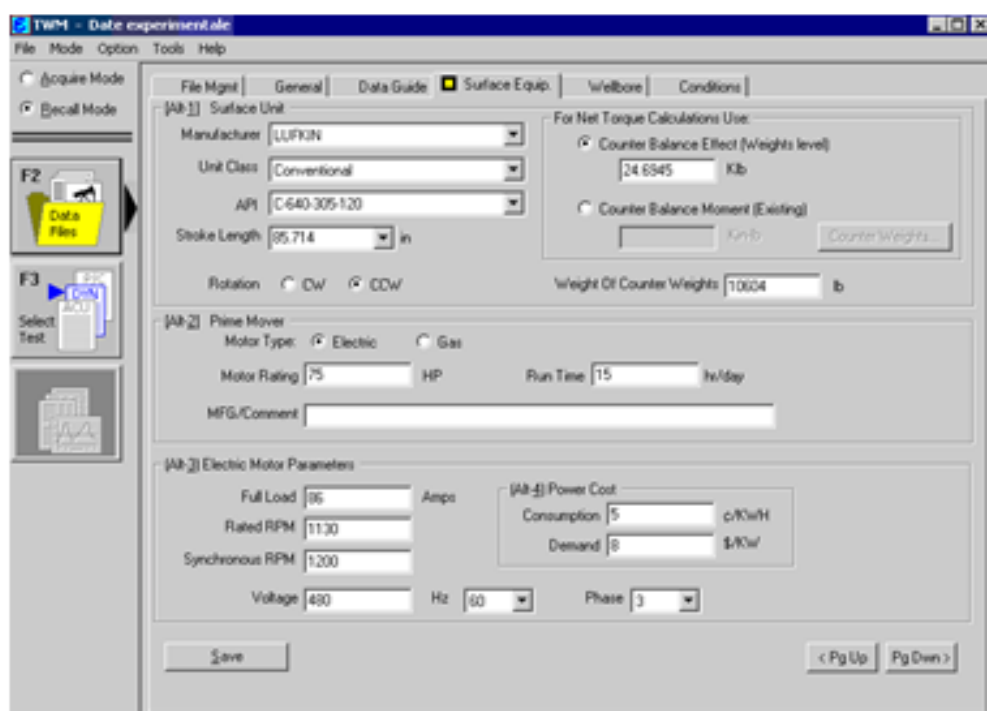

Fig. 1. Data on C-640D-305-120 pumping unit 


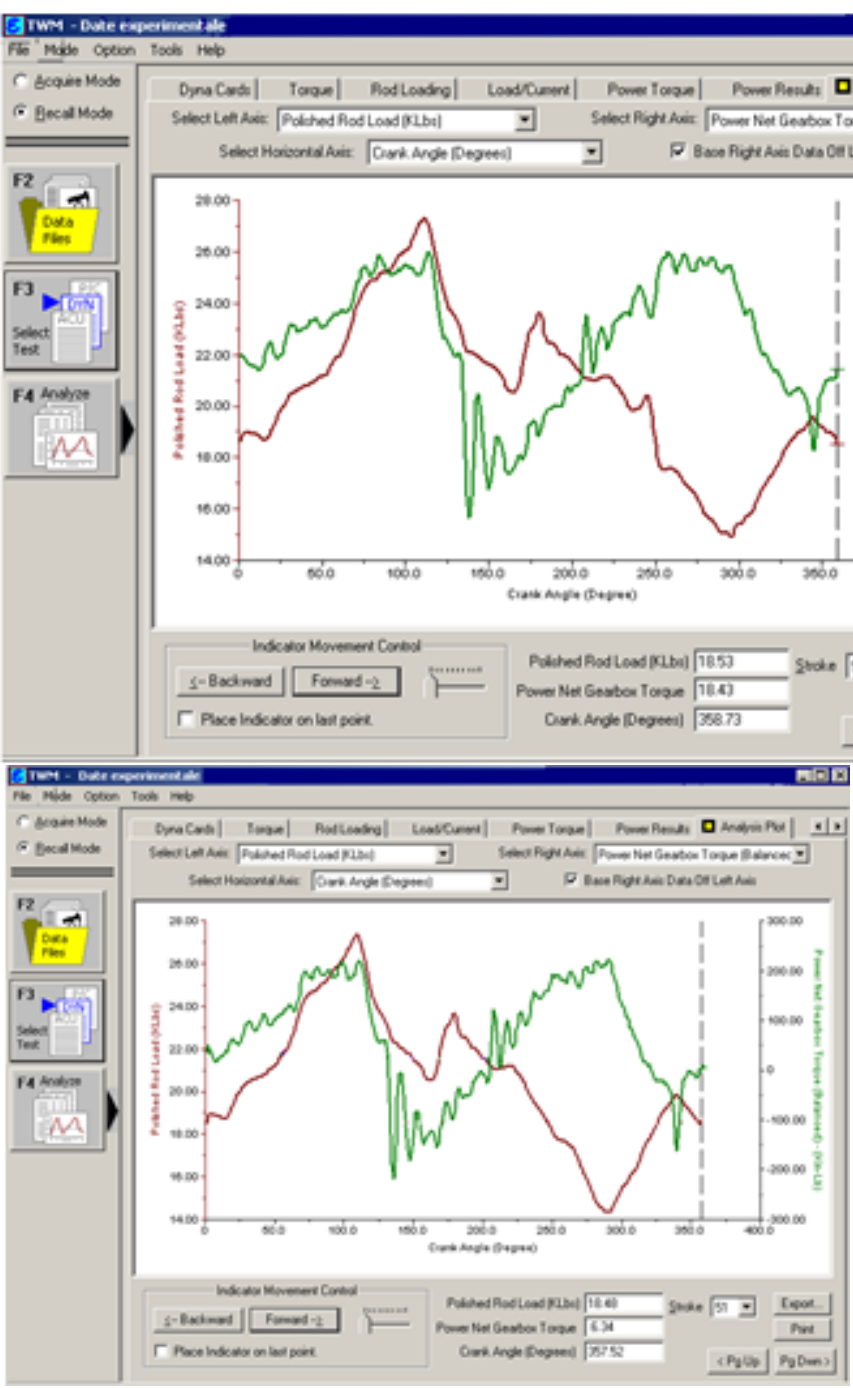

Fig. 3. The variation of the force at the polished rod and of the motor moment at the crankshaft during the stroke 51

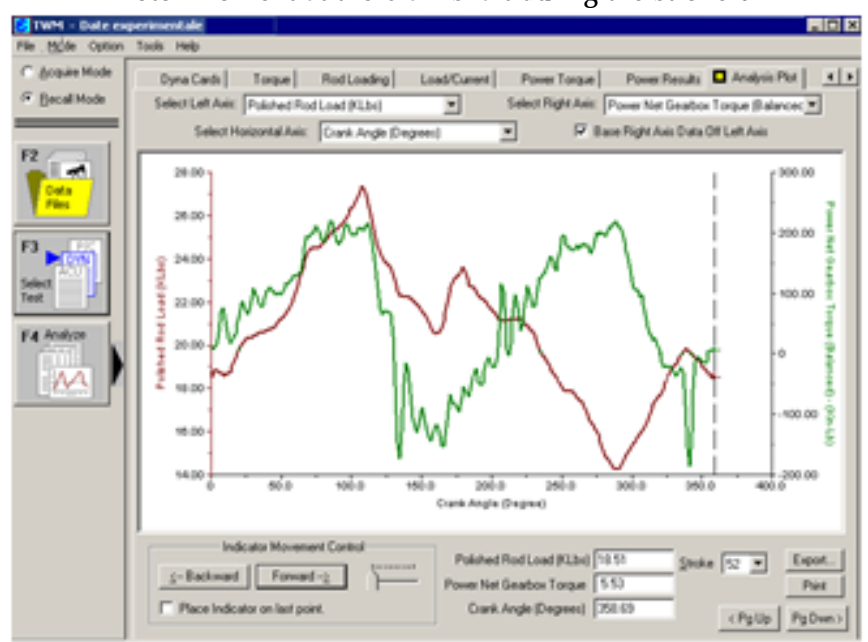

Fig. 4. The variation of the force at the polished rod and of the motor moment at the crankshaft during the stroke 52

Predictive calculation model of the motor moment at the crankshaft

The predictive calculation model having the structure of a difference equation that relates the motor moment $M$ at the crankshaft of a conventional pumping unit with the force $\bar{F}$ at the polished rod (fig. 6) is considered to have the following form [10]:

$$
A\left(z^{-1}\right) M_{m}(k)=B\left(z^{-1}\right) F(k-d)+a_{0}
$$

where the sampling angle $\Delta \varphi_{1}$ corresponding to the variation of the position of the cranks is omitted in the
Fig. 2. The variation of the force at the polished rod and of the motor moment at the crankshaft during the stroke 50

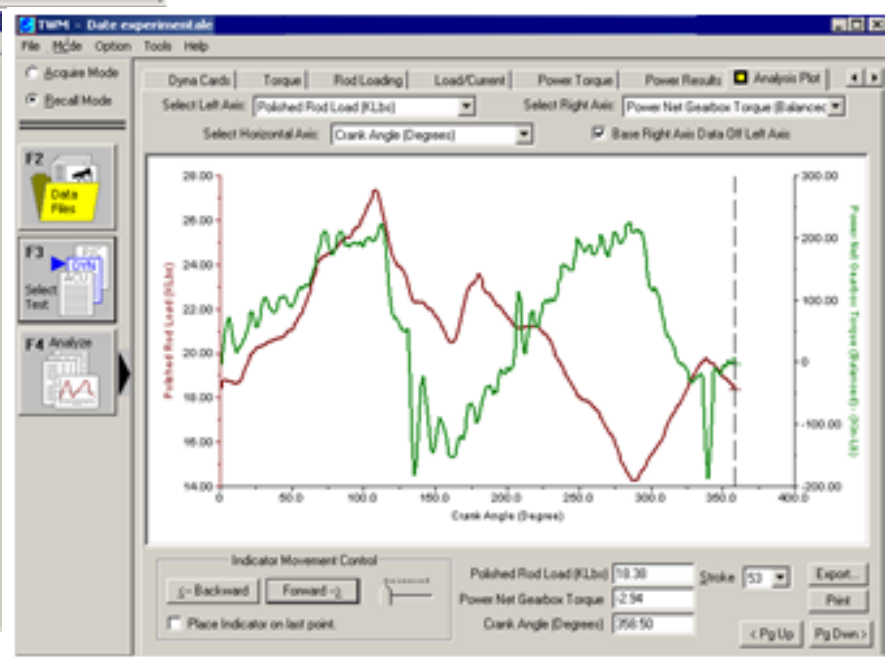

Fig. 5. The variation of the force at the polished rod and of the motor moment at the crankshaft during the stroke 53

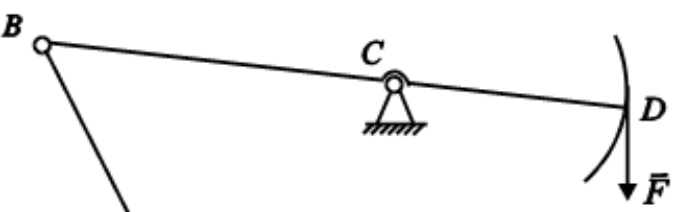

Fig. 6. The mechanism of a conventional pumping unit 
$1904684644,-1631755639,0.6147928568,0.005130103886,0.02178526886,-0.2400874732,0.5381260388,-0.5730319782,0.4266196266,-0.2874788188,0.3030743028$, $-0.4628397225,0.4276169799,-0.1709085232,-0.06372548913,0.01425672234,0.1391792745,=0.04028984383,-0.2489638254,0.3827710675,-0.4356974710,0.5558454931$ $-0.5601692116,03309536654,-0.09965627931,-0.002375387212,0.03325793745,-00529836607,0.1619244540,-0.2938811190,02998295970,-0.1470338776,-0.1673450003$.

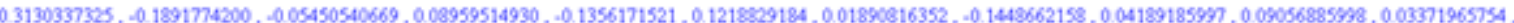
$-0.3382000692,0.4633219991,-0.3326459259,0.1815227493,-0.1102406253,0.05935590749,0.02690851319,-0.1002143674,-0.005493435810,-0.000667533972,0.1484117320$, $-0.2267274377,0.1136583749,-0.01510658812,0.000645180489,0.01212635557,-0.1141454843,0.07465650592,0.1817314949,-0.3608304359,0.2982589784,-0.2888311752$, $02809338351,-01358122917,-018941220067,03377571233,-01858611375,003079579042,004806422482,01141479797,-007329011006,003177494544,-01096139593$. $0.08900970208,-0.008342071472,-0.1285269225,0.2065028908,-0.2526548743,0.2145477711,0.007390807430,-0.2945658774,0.2936955561,-0.04348717746,-0.2154130273$. $0.2351796001,-0.1246943052,0.06537079741,-0.1561566293,0.2556932050,0.2926840604,0.2119534643,-0.1152931776,0.07507399981,-0.1814996589,0.1357103978$, $-0.1383044921,0.1956733571,-030225600220,03679137782,-03806392652,03703853318,-04360677629,05220156450,-0.4556830173,0.2595282941,-0.09117181488$, $-0.3832560458,9.159611096,-6947677811,-18.24407788,44.56500861,-69.31357287,87.53060719, .90 .76119124,64.70107891,-8416460622,-33,12728656,47.96264296$. $-5471829347,6668600268,-7091993552$. $56.73362048,-65.83189870,77.93720457,-62.14340423,35.40337765 .8318143390,-51.12919515 .7900469949,-111.1719212$. $1228035016,-87.15037270,6303697167,56.78222866,7.303412070,60.85708754, .88 .85895146,75.28764064, .70 .24511296,84.72875864,-6182524333,6.931935137$. $1079257795,-20.14266479,59.85378599,-76.00517836,46.53534895,-21.02053577,16.79525690,-1201601855,-4306230703,27.27593691,-3372310726,3358461579$. $-57.94306087,85.49034868,-68.87159382,24.94912629,-1.644574438,-11.76562258,16.94200639,-4615852500,-10.21636525,-6776994313,47.25752793,-60.55342704$, $5507816546,-4133182620,7333233372,16,14831012,-1631166819,9844642200,-11.15919069,2938532791,-30,78916457,0.5840587567 .4130852486,-7000699221$. $58.73799978,-35.12270845,24.62009176,3.504501707,-5.662194247,-20.23339817,44.39795871,-40.17591872,13.66306050,2554800635,-6322281891,98.59454428$. $-1134142942,7434510863,-21.65811110,16.21256720,-17.35056759,-12.17838177,33.5867 m 18,-34.97555444,46.72471608,-73,32112406,8647046944,-67.43116900$.

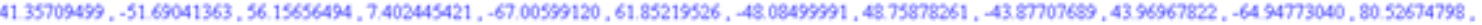
$-40.96422793,119.0612103]$

Fig. 7. The values of the parameters from vector $\alpha$

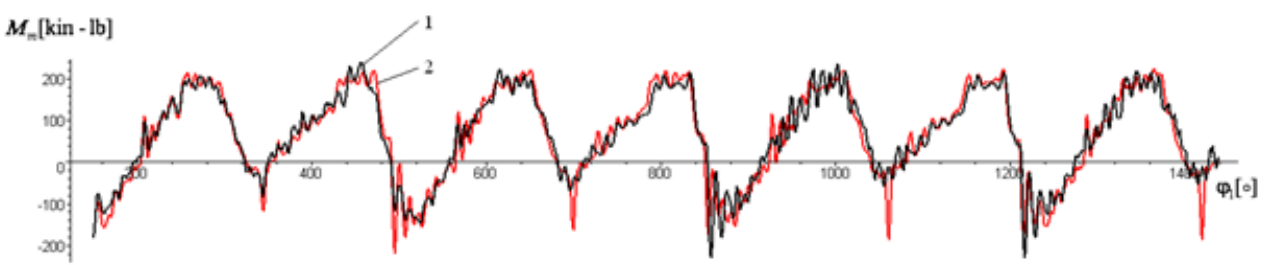

Fig. 8. The variation of the motor moment at the crankshaft during the strokes 50.53 (simulation - curve 1; experimental - curve 2)

The motor moment values recorded from measurements noted with $M_{m r}$ do not satisfy equation (1) exactly, so an equation error $\mathrm{e}(\mathrm{k})$ is introduced as follows [10]:

$$
e(k)=A\left(z^{-1}\right)\left(M_{m v}(k)-M_{m}(k)\right)
$$

Using equation (1), equation (3) becomes:

$$
e(k)=A\left(z^{-1}\right) M_{m}(k)-B\left(z^{-1}\right) F(k-d)-a_{0}
$$

The parameters $a i, b_{i}, i,=0.1 \ldots n$, grouped in the vector: $\alpha=\left[a_{1} \ldots a_{1} b_{0} . . b_{n} a_{0}\right]^{\top}$ are determined by minimizing a quadratic functional $\mathrm{E}(\alpha)$ with respect to $\alpha[10,11]$ :

$$
E(\alpha)=\frac{1}{N+1} \cdot \sum_{k=n}^{n+N} e^{2}(k)
$$

where $(n+N) . \Delta \varphi_{1}$ is the angle corresponding to the last estimation of the motor moment.

The values of the parameters $a_{i}, b_{i}, i=0.1 \ldots n$ $a_{i}, b_{i}, i=0,1 \ldots n$, may be established from the relation [10]:

$$
\begin{gathered}
\alpha=\left[S^{\mathrm{T}}(n+N-1) \cdot S(n+N-1)\right]^{-1} . \\
\cdot S^{\mathrm{T}}(n+N-1) \cdot Y(n+N)
\end{gathered}
$$

where $S(n+N-1)$ and $Y(n+N)$ are derived as follows:

$$
S(n+N-1)=\left[\begin{array}{c}
\Phi^{\mathrm{T}}(n-1) \\
\Phi^{\mathrm{T}}(n) \\
\vdots \\
\Phi^{\mathrm{T}}(n+N-1)
\end{array}\right]
$$

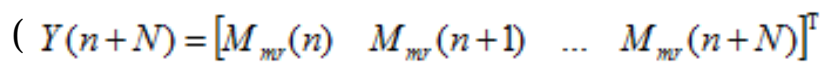

The vectors $\Phi$ in (7) have the following form:

$$
\Phi(k-1)=\left[M_{m v}(k-1) M_{m v}(k-2) \cdots\right. \text {. }
$$

$$
F(k-n-d) 1]^{\mathrm{T}}, k=n, n+1, \ldots n+N
$$

By substituting the values of the parameters , obtained with relation (6) into relation (1), is obtained the variation of the motor moment with the predictive model that provide the best fit with the recorded values.

\section{Simulation results and discussions}

The calculation methodology presented above has been transposed by the authors of the paper into a computer program using Maple programming environment. The relation that relates the motor moment at the crankshaft to the force at the polished rod has been considered to have the following form:

$$
\begin{aligned}
& M_{m}(k)=a_{0}+\sum_{j=1}^{110} \alpha[j] \cdot M_{m}(k-j)+ \\
& +\sum_{j=1}^{109} \alpha[j+110] \cdot F(k-j)
\end{aligned}
$$

where the unknown parameter vector $\alpha$ has the following form:

$$
\alpha=\left[a_{1} a_{2} \ldots a_{110} b_{0} b_{1} \ldots b_{108} a_{0}\right]^{\mathrm{T}}
$$

For determining the parameters $a_{i}, \bar{i}=0.110$ and $b_{i}$, $i=0.108$ has been used the recorded values of the motor moment at the crankshaft and of the force at the polished rod for the strokes 50 and 51 (figs. 2 and 3). In figure 7 are presented the values of these parameters in the order in which they are found in vector $\alpha$.

In figure 8 the curve 1 represents the variation of the motor moment at the crankshaft during the strokes 50,51, 52 and 53 obtained using the relation (10) and the curve 2 corresponds to the variation of its measured values.

Figure 8 highlights a very good accordance between the experimental and simulation results, practically the curve obtained after simulation track all the small variations of the experimental values of the motor moment at the crankshaft. 


\section{Conclusions}

In this paper it has been presented a predictive calculation method of the motor moment at the crankshaft of the conventional pumping units depending on the force atthe polished rod. The estimation of the model parameters has been done using the least sum of squared errors method. It has been analyzed in this way the accordance between the experimental results obtained at a well serviced by a C-640D-305-120 pumping unit and the results obtained after the simulations performed with a computer program developed by the authors using Maple programming environment.

\section{References}

1.POPOVICl, A., Equipment for the exploitation of oil wells (in Roumanian), Technical Publishing House, Bucharest, 1989

2.GIBBS, S G., Predicting the behavior of sucker-rod pumping systems, Journal of Petroleum Technology, 1963 (J uly), p. 769-778

3.GIBBS, S G., Computing gearbox torque and motor loading for beam pumping units with consideration of inertia effects, Journal of Petroleum Technology, 1975 (September), p. 1153-1159
4.TOMA, G., PUPAZESCU, A., BADOIU, D., On the Calculus of the Motor Moment of a Sucker Rod Pumping Unit, Petroleum-Gas University of Ploiesti Bulletin, Technical Series, Vol. LXVII, No. 4, 2015, p. 15-20 5.BADOIU, D., TOMA, G., Research concerning the identification of some parameters of a sucker rod pumping unit, Rev. Chim. (Bucharest), 68, no. 10, 2017, p. 2289-2292

6.BADOIU, D., Dynamic analysis of mechanisms and machines (in Roumanian), Didactical and Pedagogical Publishing House, Bucharest, 2003

7.*** Total Well Management Help Manual, Echometer Company, Texas 8.MONAGAN, M.B., GEDDES, K.O., HEAL, K.M., LABAHN, G., VORKOETTER, S.M., MCCARRON, J ., DEMARCO, P., Maple Introductory Programming Guide, Maplesoft, a division of Waterloo Maple Inc., 2005

9.*** Conventional Crank Balanced Pumping Units, Lufkin Oilfield Products Group, Houston, Texas

10.KOIVO, J., Fundamentals for control of robotic manipulators, Wiley, 1989

11.*** Press, W.H., Flannery, B.P., Teukolsky, S.A., Vetterling, W.T., Numerical recipes - The art of scientific computing, Cambridge University Press, 1986

Manuscript received: 17.04 .2018 